\title{
LA VOCACIÓN SACERDOTAL Y RELIGIOSA EN LA HISTORIA DE LA IGLESIA RECIENTE
}

DOI: https://doi.org/10.52039/seminarios.v60i212.202

\author{
FIDEL GONZÁLEZ*
}

\section{ANOTACIONES A LA VOCACIÓN Y LA ESPIRITUALIDAD SACERDOTAL}

1. El 11 de junio de 2010, en la homilía de la misa celebrada en la plaza de San Pedro al final del Año sacerdotal, Benedicto XVI reafirmaba que el sacerdote no es simplemente el "detentor de un oficio», sino el que habla en nombre de Cristo, pronunciando palabras «que abren el mundo a Dios y lo unen a Él... El sacerdocio es, pues, no mero 'oficio', sino sacramento: Dios se sirve de un pobre hombre para estar, a través de él, presente para los hombres y actuar en su favor» ${ }^{1}$.

En la historia de la Iglesia encontramos también, desde los inicios, hombres que se consagran totalmente a Cristo siguiendo los así llamados «consejos evangélicos». "Son un don divino que la Iglesia ha recibido de su Señor y, con su gracia, ha conservado siempre» (LG 43-44).

De estos dos aspectos vocacionales, coesenciales en la vida carismática de la Iglesia, se puede presentar bien su trayectoria histórica, con sus problemáticas históricas, los momentos de gran luz y también los de sombra, que demuestran que el Espíritu Santo ha estado siempre operante en esta historia. Dado que no es posible presentar aquí tal recorrido histórico, nos contentaremos con ofrecer algunas notas sobre la pastoral vocacional en tiempos más recientes.

2. Hans Urs von Balthasar, hablando de la historia de la santidad y su relación con la teología, señala que los santos deberían ser para los teólogos una ulterior explicación de la revelación, un enriquecimiento y una profundización de la verdad de la fe. Aunque no fueran teólogos de profesión, su existencia constituye un

* Fidel González Fernández es misionero comboniano. Profesor de Historia eclesiástica en la Pontificia Universidad Urbaniana y profesor invitado en la Pontificia Universidad Gregoriana de Roma. Consultor de la Congregación para las causas de los santos y la Congregación para la evangelización de los pueblos.

1. En L'Osservatore Romano, 12.6.2010. Sobre la naturaleza del sacerdocio, la formación y el ministerio sacerdotal, cf. J. Ratzinger, La Iglesia, Madrid 1991, relación introductoria al Sínodo de Obispos de 1990 sobre «vida sacerdotal y formación sacerdotal»; Id., Perspektiven der Pristerrousbildung heute, en K. Hillebrand (ed.), Vuse Auftrag, Echer, Würzburg 1990 [Perspectiva de la formación sacerdotal hoy]; Id., Ministerio y vida de los presbíteros, en Simposio del XXX aniversario del Decreto «Presbyterorum Ordinis», Città del Vaticano, 23-28.10.1995; L. Giussani, Vita e Spirito nel sacerdote cattolico, en la Sesión plenaria de la Congregación para el Clero sobre el tema «Vida, ministerio y formación permanente de los sacerdotes», Roma 19.10.1993. 
fenómeno teológico que contiene una doctrina vivida, dada por el Espíritu Santo y, por ello, digna de la máxima atención, adecuada a los tiempos y que nadie puede dejar pasar en silencio porque es presentada a toda la Iglesia². Lo mismo se aplica al hablar de la espiritualidad sacerdotal y religiosa.

Es necesario, pues, recorrer someramente la historia de la Iglesia para captar el sentido de la vocación sacerdotal y el de la vida consagrada, así como la misión que Dios realiza en la Iglesia a través de los sacerdotes y los consagrados ${ }^{3}$. Por esto, se podría también escribir una historia de la forma del vivir sacerdotal y ministerial y de la vida consagrada en la Iglesia desde el principio hasta nuestros días, una historia de gracia y carismas, donde en cada época se han resaltado algunos aspectos peculiares. Estos aspectos emergen no sólo a través de documentos del Magisterio de cada época y en tratados escritos con ese fin ("escuelas de espiritualidad sacerdotal»), sino que nacen sobre todo gracias a figuras de santos sacerdotes y religiosos de cada época.

3. La llamada a ser servidores del pueblo sacerdotal y a religiosos no es una llamada separada del Bautismo. Es más bien signo y estímulo de la caridad, que es para todos el «vínculo de la perfección» (Col 3,14$)$. Todo cristiano está llamado a la santidad (LG 39-41), la cual consiste en la plena adhesión y pertenencia a Cristo. Todo el pueblo sacerdotal, constituido en el Bautismo, está llamado a la

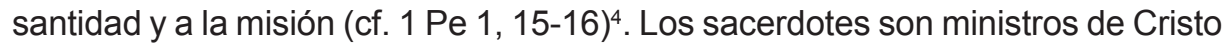
en la Iglesia que prestan un servicio de signo sacramental en este camino de santidad y de apostolado, y los consagrados, un signo escatológico. Su santidad personal debería ser un estímulo y una memoria de Cristo para todos 5 .

4. Los sacerdotes están llamados a guiar la comunidad como pueblo sacerdotal; éste debe encontrar en ellos un signo y un estímulo de la caridad del Buen Pastor que inmoló su vida por sus ovejas (cf. Jn 10). Por esto, en la historia de la Iglesia se ve que la renovación del pueblo depende siempre, en gran parte, del

2. Cf. H. U. von Balthasar, Sorelle nello Spirito. Teresa e Isabella di Digione, Introducción, Milano 1979, 17-32.

3. Cf. Id., La grazia e il carisma, en Sponsa Christi, Brescia 1969, 297-309; según von Balthasar los miembros de la jerarquía deben orientar su acción al servicio de los laicos hasta el punto de concebirlo y ejercerlo más como carisma que como ministerio, Cf. J. Ratzinger, Ministero e vita dei presbiteri, artículo citado en la nota 1.

4. J. Ratzinger, hablando de la «institución y carisma en el sacerdocio ministerial», señala que «el ministro ordenado no solo no está dispensado de realizar siempre en sí mismo la exigencia del amor de hijo de Dios, dignidad recibida en el bautismo sino en el ejercicio de su ministerio solo consigue su objetivo realizando el único verdadero sacrificio y la única verdadera ofrenda de Cristo en sus dos aspectos objetivo y subjetivo». Cf. Ministero e vita dei presbiteri; I Movimenti ecclesiali e la loro collocazione teologica, en I movimenti nella Chiesa, Città del Vaticano 1999. Cf. también G. Chantraine, Carismi e movimenti nella Chiesa; E. Corecco, Profili istituzionali dei movimenti nella Chiesa, en I Movimenti nella Chiesa negli anni '80, Milano 1982, 203-304 (sobre los términos "objetivo" y «subjetivo», cf. p. 120); I. Biffi, Il battesimo e l'identificazione dell'uomo ossia l'antropologia cristiana, en I laici e la loro missione nella Chiesa, Milano 1987, 13-26; P. Fransen, Sacerdozio, en Dizionario Teologico III, Brescia 1968, 184.

5. Cf. L. Giussani, Dio: il tempo e il tempio, Appunti di una conversazione con un gruppo di Memores Domini, (26 novembre 1994): Tracce -Litterae Communionis 1 (1995). 
reconocimiento de Cristo como único Señor por parte de los sacerdotes, los cuales, como recuerda la Presbiterorum Ordinis, «deben esforzarse por alcanzar una santidad cada vez mayor para convertirse cada día en instrumentos más aptos para el servicio de todo el pueblo de Dios» (PO 12). Las diversas «espiritualidades y estilos de vida sacerdotales», así como las diversas formas de consagración religiosa, han nacido siempre en la Iglesia por carismas específicos a través de santos concretos. Por esto, tal comunicación viene a través del método del encuentro, que, porque es algo verificable, sucede en lugares históricos y mediante circunstancias y rostros concretos. Justo aquí se inserta el misterio de la Iglesia, inseparable del misterio de Verbo encarnado, Cristo, y también por sacerdotes y religiosos hasta poder hallar a Cristo mirando a los santos sacerdotes.

5. ¿Cómo ha visto la Iglesia, a lo largo de los siglos, la figura del sacerdote? ¿Cómo el Espíritu de Cristo presente siempre en la Iglesia ha suscitado sin cesar carismas para la renovación de la vida sacerdotal y consagrada? Si miramos la historia de la Iglesia, desde los apóstoles hasta hoy, constatamos momentos de indecisión y nubosidad, pero seguidos siempre de momentos de luz. El método ha sido siempre el de las gracias o carismas oportunos. He aquí por qué conviene mirar a las figuras sacerdotales y religiosas más significativas de la historia de la Iglesia para aprender de ellas y seguir su pista. Estas figuras sacerdotales han sido a lo largo de la historia de la Iglesia como la revelación de la presencia sacerdotal de Cristo Buen Pastor y de su relación filial con el Padre.

\section{MAGISTERIO PONTIFICIO SOBRE LA NATURALEZA DE LA VOCACIÓN EN LA ÉPOCA CONTEMPORÁNEA ${ }^{6}$}

Si nos limitamos a la época contemporánea, tras el ciclo histórico inaugurado a partir de la Revolución francesa asistimos a cambios profundos en la promoción y formación sacerdotal y religiosa, determinados también por los acontecimientos sociales y políticos. Las nuevas situaciones sociales y culturales ponen a la Iglesia frente a la necesidad de clarificar más el sentido de la vocación; al mismo tiempo nacen en la Iglesia nuevos movimientos eclesiales que se convertirán más adelante en un campo fecundo para las vocaciones eclesiales en los diversos estados de vida ${ }^{7}$. He aquí algunos destacados:

1. La legislación liberal sobre corporaciones religiosas, las supresiones de los religiosos y de los seminarios, las continuas guerras y desbarajustes sociales llevan a un relajamiento de la vida religiosa y al abandono voluntario o forzado de no pocos religiosos. A pesar de todo, nacen muchos institutos religiosos, no pocos de los antiguos se renuevan y surgen también nuevas formas de vida

6. M. Oscar Llanos, Servire le vocazioni nella Chiesa: donde el autor ofrece un recorrido del camino de la pastoral vocacional. También: V. Magno, Pastorale delle vocazioni, nn. 17-60.

7. F. González Fernández, I movimenti. Dalla Chiesa degli Apostoli ad oggi, Milano 2000. 
consagrada. En la historia de la piedad cristiana, entre el siglo XIX y el XX destacan algunos aspectos, como una piedad centrada en la misericordia divina, el misterio de la encarnación, de la salvación universal de Cristo y de su gracia ofrecida a todos, en respuesta a las tendencias jansenistas de la época anterior, una sentida piedad eucarística y la apertura, inicialmente tímida, del movimiento litúrgico y la comunión frecuente ejercieron un notable influjo en la promoción vocacional, la formación de los sacerdotes y las nuevas formas de vida sacerdotal. Por lo cual, pese a las graves crisis en marcha, brota un fuerte movimiento de resurgir cristiano, con un tipo de obispo y sacerdote nuevo, más pastoral. Vivimos una gran admiración a los sacerdotes y atracción por la vocación sacerdotal y religiosa. Es innegable que el despertar de la vida cristiana en este periodo de fuertes contrastes y hostilidad contra la Iglesia había tenido efectos beneficiosos en la promoción vocacional y en la formación sacerdotal y religiosa.

2. La serie de reformas comienza con la nueva situación creada tras la caída de Napoleón ya desde Pío VII. Será especialmente Pío IX (1846-1878) quien actúe en este sentido con tenacidad, pese a las dispersiones liberales. En octubre de 1846 instituye la nueva «Congregación sobre el estado de los regulares», que se mueve en varias direcciones: a) mejor selección de candidatos (1848); b) introducción de la vida común en noviciados y seminarios religiosos; c) la circular «Neminem Latet» (19.3.1857) impone a los institutos masculinos un trienio de votos simples en lugar de la inmediata profesión solemne; d) cuidado en la elección de los superiores generales. Pío IX además insiste en la promoción de candidatos al sacerdocio idóneos: «Solo clérigos adolescentes bien formados desde tierna edad ${ }^{8}$, fácilmente educables, pero previniendo también contra la presión de las familias para que sigan la vocación sacerdotal o religiosa, a menudo simplemente por motivos de carácter social ${ }^{9}$.

3. Con el movimiento misionero surgen nuevos seminarios misioneros. Propaganda Fide tiene en el corazón la formación de seminarios indígenas; su historia es una continua llamada a tal deber ${ }^{10}$. Estas directrices serán recogidas enseguida por Benedicto XV en la encíclica Maximum illud ${ }^{11}$. En esta panorámica de conjunto del largo siglo liberal encontramos algunos aspectos destacables, como la insistencia en la plegaria por las vocaciones, o la difusión de textos vocacionales (animación vocacional: encuentros y revistas). En este campo se distinguen, entre otros, algunos fundadores misioneros, como san Daniel Com-

8. P. Gianola, Magisterio y Pastoral de las Vocaciones, en Diccionario de Pastoral Vocacional (DPV), Salamanca 2005, 658-668.

9. En tal sentido insisten los mismos Pontífices (Encíclica Cum nuper de 1858) y varios sínodos diocesanos y provinciales como los de Soisson de la provincia de Reims (1849); Rennes de la provincia de Tours (1849); Halifax (1857); Gran (Strigonium, Ungheria, 1858); Köln (1860), Ibid., 659-662.

10. Con instrucciones continuas: $1659,1845,1865,1869$ y 1883. Para la primera, cf. Collectanea SCPF, II,1346 (cf. Memoria rerum III/2, 750-759); para la segunda, ibid., 1606.

11. Benedicto XV, Carta encíclica Maximum illud (30.11.1919), en AAS, (1919), 448. 
boni. Los fundadores del XIX y principios del XX inician y difunden las escuelas apostólicas o seminarios menores de adolescentes con este fin. Se crean también las revistas misioneras, como la de «Propagación de la fe» de Lyon (Paulina Jaricot), la fundada en Italia por el mismo Comboni («Anales del Buen Pastor») y otras con clara finalidad vocacional.

Estas iniciativas crecen a comienzos del siglo XX, cuando nace también la primera revista específicamente vocacional por obra del P. Delbrel en 1901. Sigamos su recorrido a través de los sucesivos pontificados.

\section{PíoX}

San Pío X (1903-1914) marca una nueva etapa en la historia del magisterio sobre la vocación sacerdotal y religiosa, incluso con sus numerosas reformas en el campo pastoral y jurídico. Con su encíclica $E$ supremi (1903), de fuerte acento cristológico, pide la formación del sacerdote como un alter Christus: «Cristo sea formado en aquellos a los que se les encomienda formar a Cristo en los otros ${ }^{12}$. Son los tiempos de Dom Columba Marmion (1858-1923), antiguo alumno del Pontificio Colegio Urbano de Propaganda Fide, y abad benedictino de Maredsous (Bélgica), con sus libros Jesucristo, vida del alma (1917), Jesucristo en sus misterios (1919) y Jesucristo, ideal del monje (1922). Se insiste en aspectos como una buena instrucción, un cuidado de las vocaciones (discernimiento), integridad moral, cautela en la selección, porque tal como sean los sacerdotes así serán las almas a ellos confiadas. Ya en este periodo se fundan por doquier seminarios menores y escuelas apostólicas, también en zonas de misión, donde son una de las primeras preocupaciones de los misioneros apenas iniciada su labor.

Hasta los tiempos de san Pío X la atracción por el sacerdocio era considerada uno de los factores fundamentales de la vocación al sacerdocio, la «atracción vocacional», como la había definido Gautrelet ${ }^{13}$. En 1909 aparece el libro de Joseph Lahitton, profesor en el seminario de Aire et Dax, La vocación sacerdotal, que se propone estudiar la verdadera naturaleza de tal vocación, para superar ideas que se convierten en prejuicios en la selección vocacional y en la formación al sacerdocio. Lahitton sostiene que la vocación «es la elección de la llamada de un sujeto al estado eclesiástico; elección y llamada gratuitas, que Dios hace desde toda la eternidad y que manifiesta y exige en el tiempo a través de los ministros legítimos de la Iglesia» ${ }^{14}$. Esta concepción de la vocación implica, entre otras cosas, que la vocación sacerdotal se identifica con la llamada del obispo; que la ordenación sacerdotal no es un derecho que el sujeto adquiera por el mero hecho de desearla; la vocación no se manifiesta por inspiración del Espíritu, mociones

12. P. Gianola, en DPV, 659-660.

13. En su Traité de l'etat religeux I, 230, citado en R. Izard, La pastoral de las vocaciones en la Iglesia, 139. Seguimos aquí esta obra y M. O. Llanos, Servire le vocazioni nella Chiesa, 45-46.

14. J. Lahitton, Traité de l'etat religeux I, 230, citado en R. Izard, La pastoral de las vocaciones en la Iglesia, 139. 
de la gracia e inclinaciones. Esto para evitar ilusiones, presunciones e individualismos; la vocación no coincide con las actitudes o la idoneidad del candidato, que sólo es sujeto pasivo de la elección vocacional; por lo cual, no hay hechos infalibles de llamada vocacional de parte de Dios, a excepción de la llamada del obispo, que constata, comunica y da la vocación.

La posición de Lahitton provocó fuertes reacciones en muchos, hasta el punto de que Pío $X$ decidió encargar el estudio del problema a una comisión cardenalicia. El 12 de junio de 1912, dicha comisión escribe al obispo de Aire et Dax aprobando algunas tesis de Lahitton, sobre todo las de que ninguno tiene derecho a la ordenación sin la llamada del obispo; que la vocación no se manifiesta en la atracción interior del sujeto; al ordenando se le exige la recta intención junto con la idoneidad; ésta consiste en dones de naturaleza y gracia, vida moral digna y ciencia suficiente para cumplir los deberes del ministerio. La comisión no confirmó la posición de Lahitton que consideraba la llamada del obispo como el elemento esencial y único de la vocación. Pero tampoco la reducía al mero deseo. Tres de los elementos señalados tradicionalmente (idoneidad del candidato, recta intención y llamada del obispo) se mantenían en la vocación, si bien el magisterio no asumía la exclusividad que Lahitton otorgaba a la llamada del obispo como elemento fundamental. El magisterio eclesiástico sobre vocaciones seguirá en esta línea hasta la encíclica de Pío XI Ad catholici sacerdotii (1935).

\section{Benedicto XV}

Benedicto XV (1914-1922) crea la Sagrada Congregación de Seminarios y Universidades de Estudios, y con el Motu proprio Seminaria clericorum (4.11.1915) organiza los seminarios según las nuevas exigencias. Su encíclica misionera Maximum illud (30.11.1919), la primera en su género, insiste en la formación del clero indígena.

\section{Pío XI}

Su sucesor, Pío XI (1922-1939), vive los años dramáticos que siguen a la Gran Guerra (1914-1918): calamidades y revoluciones sociales, regímenes totalitarios, durísimas persecuciones anti-cristianas por doquier de parte de viejos regímenes anticlericales liberales y masónicos o de nuevos regímenes totalitarios de diverso género. Abundan en esta época los seminaristas y sacerdotes martirizados.

Por eso, por un lado el papa Ratti intensifica su magisterio en la línea de Benedicto XV, insistiendo en la dimensión misionera que ha de darse a la promoción vocacional y a la formación sacerdotal. En este periodo se expanden diversos seminarios misioneros de carácter nacional, algunos erigidos ya durante los pontificados de Pío IX y León XIII, y que habían dado origen al nacimiento de diversos institutos misioneros ad gentes bajo Propaganda Fide; otros se crean precisamente a lo largo de este pontificado, y en cada país católico destacan figu- 
ras de animadores vocacionales, como el P. Paolo Manna, fundador de la Unión Misionera del Clero, en Italia, y nace una literatura misionera de fondo vocacional. Los seminarios menores en las diócesis y las escuelas apostólicas de religiosos se convierten cada vez más en lugares para formar candidatos.

Las líneas de fondo en las que el papa Ratti insiste son la necesidad de promoción vocacional frente a la penuria pastoral del momento, y la necesidad de orar con tal fin, la educación cristiana (el Papa insistía en este punto frente a una sociedad cada vez más secularizada) con la implicación de la familia, la parroquia, la Acción Católica y los movimientos laicales bajo la guía de la jerarquía, los catequistas... Estos movimientos y asociaciones, la Acción Católica en primer lugar en la mente del Pontífice, son verdaderos viveros de vocaciones sacerdotales y religiosas, si se cuidan debidamente. En este contexto destacan los seminarios menores en su rol educativo de posibles candidatos al sacerdocio y a la vida religiosa, y también el magisterio pontificio sobre la vocación en el siglo XX y todo el bagaje del magisterio relativo tanto a la vida sacerdotal como a la religiosa.

La encíclica Ad catholici sacerdotii abre una nueva época en la teología y la praxis vocacionales. En ella Pío IX enuncia la naturaleza, los signos y los medios para promover y sostener la vocación sacerdotal. Subraya también la necesidad de atender a las cualidades a la hora de la promoción vocacional, y señala la oración como el medio principal para su promoción. Señala las asociaciones católicas, en especial la Acción Católica, como vocaciones de laicos al apostolado y vivero de vocaciones. En este sentido, el Papa ofrece indicaciones sobre la vocación de cada cristiano, e indica que «quien se orienta al sacerdocio únicamente por el noble motivo de consagrarse al servicio de Dios y a la salvación de las almas y ha adquirido, o intenta adquirir, una sólida piedad, una pureza de vida a toda prueba, una ciencia suficiente en el sentido expuesto por Nos, esto demuestra claramente haber sido llamado por Dios para el ministerio sacerdotalı ${ }^{15}$. Y a continuación el Pontífice subraya el valor de la atracción vocacional y los signos de idoneidad, tanto físicos como morales, según la doctrina tradicional de la Iglesia. En este sentido el Papa asume la antigua doctrina según la cual se pueden determinar los signos del Espíritu en una llamada vocacional. También en este periodo encontramos figuras sacerdotales que insisten en el tema vocacional al sacerdocio, como san Annibale di Francia, Giacomo Alberione y Giacomo Russolino en Italia.

\section{Pío XII}

Toca a Pío XII regir la Iglesia en los dolorosos años de la Segunda Guerra Mundial, la post-guerra y el periodo de la guerra fría, que son también años de una transformación galopante del mundo en el sentido de la secularización, las

15. Pío XI, Encíclica Ad catholici sacerdotii (20 diciembre 1935), AAS 28 (1936), 37-52. 
persecuciones contra la Iglesia en el mundo comunista, la conquista de la independencia de muchos países hasta ahora dominados por el Occidente colonial y la expansión positiva de la actividad misionera de la Iglesia. En este contexto cobra cada vez más importancia el papel del laico, el fuerte y decidido inicio de movimientos eclesiales laicales contemporáneos, y también nuevas experiencias en la formación y en la vida de los sacerdotes y religiosos, así como el decidido surgimiento de nuevas formas de vida consagrada, como los institutos seculares y semejantes. Por otra parte, también los seminarios diocesanos y religiosos crecen y se llenan, quizás como consecuencia de las escasas posibilidades educativas para las clases obreras y campesinas de la postguerra. La primera gran encíclica del papa Pacelli, Summi pontificatus (20.10.1941) abre nuevas perspectivas sobre la vocación al sacerdocio y a la vida consagrada ${ }^{16}$.

En el campo vocacional se crea la Pontificia Obra para las Vocaciones eclesiásticas [Normae ad statuta exequenda] bajo la Sagrada Congregación de Seminarios y Universidades de Estudios, con el Motu proprio de Pío XII Cum nobis $(4.11 .1941)^{17}$, que se preocupa fundamentalmente de fomentar la oración por las vocaciones: fórmulas de oración e indulgencias concedidas. Dicho Motu proprio se divide en tres capítulos: en el primero se presenta la obra creada, el segundo habla de su erección jurídica, y el tercero de las directrices para el fin. Siguen tras este documento las Normae Exsequenda per POVP: finalidad y fin y medios para la difusión de la Obra; se habla de la naturaleza y excelencia del sacerdocio, la promoción de ofrecimiento de misas, oraciones y sacrificios por las vocaciones sacerdotales, invitando a apoyar y difundir la obra en las diócesis. La obra es consagrada a Cristo sumo y eterno sacerdote bajo la protección de la Virgen y de san José. La POVP se presenta como una persona moral, no colegiada, de derecho pontificio, gobernada por un presidente y un vicepresidente.

Hay que notar que ya mucho tiempo atrás habían nacido en diversos países obras en esta línea con apóstoles para la oración en favor de las vocaciones sacerdotales y de su santificación, a menudo acompañadas de fundaciones consagradas a este fin. Un ejemplo es el de España, que ya en tiempos de tribulación durante la persecución religiosa y precisamente en 1936, el sacerdote José María García Lahiguera, formador de sacerdotes durante aquellos atribulados años y futuro obispo de Madrid y después arzobispo de Valencia, promueve varias iniciativas en este sentido y funda un Instituto de vida contemplativa «Oblatas de Cristo Sacerdote», y promueve la fiesta litúrgica en honor de Cristo sumo y eterno sacerdote, para el jueves posterior a la celebración del Sagrado Corazón de Jesús ${ }^{18}$.

16. Pío XII, Summi Pontificatus (20 octubre 1939), in AAS 31 (1939) 413-453.

17. Pío XII, Motu proprio Cum nobis de Pontificio Opere Vocationum Sacerdotalium apud S. Congregationem Seminariis et Studiorum Universitatibus praepositum costituendo (4 noviembre 1941), ASS 33 (1941) 79.

18. Congregatio de Causis Sanctorum P. N. 2051, Madrid. Beatificationis et Canonizationis Servi Dei losephi Mariae García Lahiguera Archiep. Valentin. Fundatoris Congr. Sorr. Oblatarum a Christo Sacerdote (1903-1989). Positio super vita, virtutibus et fama sanctitatis. Romae 2010. 
Esta obra (POVE) adquirirá más amplias funciones con el Vaticano Il cuando Optatam totius insista en la responsabilidad de toda la comunidad en esa dirección (n. 2) ${ }^{19}$. Christus Dominus (n. 2) insta a que la obra se convierta en una preocupación de toda la iglesia a niveles más amplios. La obra había nacido con el fin principal de preocuparse de las vocaciones sacerdotales, y aunque más de uno había propuesto en el Concilio la extensión también de la finalidad a todas las vocaciones, la Congregación para la Educación Católica ha tenido siempre la idea de conservar su nombre original, que indica el fin esencial de la misma obra ${ }^{20}$.

Otra dimensión en la cual insiste el magisterio de Pío XII en el campo vocacional es el papel de la familia cristiana como vivero de vocaciones, y específicamente la función de la madre. En la encíclica Mystici Corporis (26.6.1943), el Papa sitúa la temática de la vocación en la perspectiva cristológica y eclesiológica. El 2 de noviembre de 1947 publica la constitución Mater Ecclesiae, con la apertura y reconocimiento de los Institutos Seculares y además fomentando las llamadas vocacionales en tal sentido dentro de la Iglesia, especialmente junto a las asociaciones católicas en tiempos en los que ya se hacen notar las dificultades vocacionales y la necesidad de vocaciones. El Papa se preocupa de todas las vocaciones a la vida religiosa, consagrada en sus diversas modalidades masculinas y femeninas. En este último sentido hay que tener en cuenta su Constitución apostólica Sponsa Christi (21.11.1950) y la Carta encíclica Sacra virginitas (25.3.1954)21. En la Constitución apostólica Sedes Sapientiae (31.5.1956), el Papa resalta los aspectos maternos de las vocaciones religiosas femeninas, sus aspectos de plenitud humana y la necesaria formación en este sentido ${ }^{22}$. La vida cristiana tiene una unidad, los cristianos son llamados a la santidad (perfección) en todos los estados de vida ${ }^{23}$. En otro Motu proprio, Cum supremae, Pío XII completa su magisterio en el tema vocacional creando la Pontificia Obra de Vocaciones Religiosas (1955) ${ }^{24}$. Es sumamente interesante ver estos documentos en momentos precisos de la historia religiosa, cuando, por una parte, la sociedad caminaba con voluntad creciente hacia una clara secularización y, por otra, en algunos sectores se continuaba viendo la vida religiosa como una especie de grupo privilegiado y elitista dentro de la Iglesia ${ }^{25}$.

19. A. Skf, Notes sur les Eglises Orientales et sur les vocations au Liban: Seminarium 3 (1984) 360-370.

20. Cf. Llanos, 49 , nota 73 , donde propone la ampliación de ámbito y perspectiva vocacional de la Obra.

21. Carta encíclica Sacra virginitas (25 marzo 1954), AAS 46 (1954) 161-191.

22. Sedes Sapientiae (31 mayo 1956), AAS 48 (1956) 354-365.

23. Alocución Sobre la maternidad (9 dicembre 1957) en AAS 50 (1958) 34-43.

24. Motu proprio Cum Supremae sobre la Pontificia Opera primaria de vocaciones religiosas (11 febrero 1955), AAS 47 (1955) 266; Sacra Congregazione per i Religiosi, Statuti e Norme, AAS 47 (1955) 298-301. Cf. G. Lievin, La Obra pontificia de las vocaciones religiosas, en Actas del Congreso Nacional de Perfección y Apostolado, Madrid 1956, 922-928.

25. Cf. las anotaciones de Llanos, 50-51, y nota 80. Juan Pablo II con la Constitución apostólica Pastor Bonus (28 de junio de 1988) cambió el título en «Congregación para los Institutos 
Otros momentos particularmente intensos del pontificado de Pío XII que incidieron en el tema vocacional fueron la proclamación del dogma de la Asunción de la Virgen durante el Año Santo de 1950, y el contexto cada vez más duro de la vida de las iglesias bajo la persecución comunista en muchos países del llamado «telón de acero», pero también de la intensa difusión de la actividad misionera en América Latina, Asia y África. En Europa se asiste a un intenso movimiento de expansión edilicia con la construcción de grandes seminarios que acogen centenares de adolescentes y jóvenes encaminados a la vida sacerdotal y religiosa, y también en los seminarios misioneros (el «boom» de los seminarios), pero también el decidido nacimiento de movimientos eclesiales nuevos que a menudo serán calibrados desde diversos ángulos en la misma iglesia.

En este contexto, Pío XII publica Menti nostrae, que afronta el tema vocacional y el de la formación sacerdotal, con una especie de llamada a la acción del Espíritu Santo en tal proceso. En un momento en el cual las masas de niños y jóvenes entran en los seminarios de toda clase, el Papa subraya el aspecto cualitativo en la promoción vocacional sobre el cuantitativo, que ya es a menudo predominante. Por todas partes nos encontramos con promotores vocacionales de cada instituto y de las diócesis que recorren parroquias, colegios e instituciones católicas reclutando vocaciones, con el peligro, con frecuencia real, de aceptar numerosos candidatos provenientes de familias deseosas de dar a sus hijos posibilidades educativas mejores que las que sus propios ambientes ofrecen. En este contexto se reclama una atención especial a la formación de los jóvenes reclutados, y se alude también a realidades eclesiales como la Acción Católica, calificándolas de campos privilegiados para el fomento de las vocaciones. Nacen y se difunden hojas vocacionales, especialmente para la promoción vocacional misionera. También los numerosos seminarios menores diocesanos y religiosos presentan una estructura semejante. Hay diócesis en el mundo católico que tienen nada menos que media docena de seminarios o escuelas apostólicas de esta naturaleza, que se llenan cada año con niños provenientes de todas las regiones vecinas.

\section{Juan XXIII, el Vaticano II, Pablo VI y el postconcilio}

1. Juan XXIII, fruto él mismo de una experiencia vocacional similar (seminario menor), sigue fundamentalmente en su intenso aunque breve pontificado las líneas de sus predecesores inmediatos. Pero será el Vaticano II, convocado por él, el que marcará una nueva etapa en el tema de las vocaciones en la Iglesia, así como en la formación de los llamados a los diversos estados de vida eclesial. Los documentos del Concilio señalan el tema vocacional en su objeto, naturaleza y

de Vida Consagrada y las Sociedades de Vida Apostólica». Los dos organismos pontificios referentes al tema vocacional: la POVS (Pontificia Obra para las Vocaciones Sacerdotales) y la POVR (Pontificia Obra para las Vocaciones Religiosas), aun teniendo fines vocacionales en planos diversos (diocesano y religioso), en el fondo coincidían en el tema de las vocaciones. 
fin, e insisten también en el cuidado vocacional indicando el rol tanto de la familia como de los sacerdotes, parroquias, comunidades y grupos eclesiales.

Durante el pontificado de Juan XXIII se instituye de parte de la Congregación de Seminarios la Jornada nacional por las Vocaciones (20.11.1962), que se celebra el domingo del Buen Pastor. Conviene anotar que en muchas diócesis del mundo se celebraban jornadas vocacionales por el seminario diocesano ya desde los tiempos de Pío XII (así, en España el 19 de marzo, san José).

El Concilio representa un nuevo momento en la historia de la promoción vocacional, formación y «teología» de la vocación de los candidatos al sacerdocio y la vida religiosa. Todo documento conciliar hace referencia a la vocación fundamental del cristiano que brota del bautismo y, según el carácter y objeto del documento, desarrolla el tema o da indicaciones adecuadas ${ }^{26}$. Los documentos fundamentales del Concilio entre Constituciones y Decretos son diez, ya publicados y conocidos por el gran público en traducciones de los textos originales latinos.

En la historia contemporánea de la Iglesia, el Concilio ha sido, sin duda, un punto de llegada y también un punto de partida. Este señala el inicio de una renovación en la vida eclesial, pero también, en momentos de un cambio de época tan agudo que marca el fin del así llamado «siglo breve» o de los grandes totalitarismos y guerras, un momento de crisis general social (recuérdese el «mayo del 68»), y así la Iglesia es golpeada por estos momentos, también en el campo vocacional. Las causas de la crisis, de las controversias sociales, de los debates dentro de la sociedad y de la Iglesia han sido y son objeto de numerosos análisis y estudios a los que remitimos. En el caso de las vocaciones dentro de la Iglesia, las raíces y expresiones de esta crisis responden a causas tanto externas como internas. Por todos es conocida o experimentada la crisis de la identidad sacerdotal que arrolló a la Iglesia del "postconcilio»: «Cierta extrañeza y ambigüedad del sacerdote en la vida social, la carencia de modelos sacerdotales, las frustraciones, la infelicidad e infidelidad por parte de algunos sacerdotes o consagrados $»^{27}$, y las consecuencias en la pastoral vocacional y en la formación. A estos factores se unen las situaciones de profunda crisis social, los cambios en la psicología de los jóvenes, la fragilidad y la fragmentación de la persona y la dispersión y desconcierto en el consiguiente campo educativo. En el campo de la vida sacerdotal y religiosa, el fallo vocacional, por una parte, y, por otra, el flujo de abandonos en seminarios y del sacerdocio y de la vida religiosa, fueron notables.

A pesar de las dificultades inherentes a estos años, a partir del Concilio asistimos al nacimiento de fuertes movimientos de renovación eclesial, a la renovación de los institutos de vida consagrada en sus reglas para retomar la «primigenia instituti inspiratio» en los antiguos siguiendo las indicaciones conciliares y las apli-

26. Indicaciones bibliográficas, en Llanos, 53ss; P. Gianola, in DPV, 668; R. Sacco, Congresos internacionales sobre las vocaciones de especial consagración, en DPV, 260-263.

27. Llanos, 56. 
caciones del Concilio en los diversos sectores de la vida eclesial, y el nacimiento de otros nuevos con nuevas formas de vida consagrada también.

2. A Pablo VI se debe un valioso magisterio sobre las vocaciones e indicaciones precisas para la animación vocacional a través de los numerosos y periódicos encuentros con los obispos, sacerdotes, religiosos (encuentros sobre todo con motivo de capítulos generales), animadores vocacionales y jóvenes en estos años atormentados. Sus numerosas intervenciones en este campo se pueden agrupar en documentos sinodales, instituciones creadas bajo este pontificado, las intervenciones o mensajes con motivo de las jornadas mundiales de oración por las vocaciones, y en los documentos magisteriales del Pontífice.

En primer término encontramos la Ratio Fundamentalis Institutionis Sacerdotalis del sínodo de octubre de 1967 y la de la Segunda Asamblea General del Sínodo de 1971, que elabora un documento sobre «el sacerdocio ministerial» donde se ofrecen precisas indicaciones sobre la identidad del sacerdote y propuestas sobre la promoción y formación sacerdotal.

En el segundo caso, Pablo VI relanza la «Jornada mundial por las vocaciones», título al que desde 1976 se le añaden las palabras «de oración», con las que se precisa el fin de la jornada dedicada a las vocaciones sacerdotales y religiosas, celebrada cada año en el domingo del Buen Pastor. Cada jornada está acompañada de un mensaje del Papa. Estos mensajes, de estilo claro y literariamente bello, característico de Pablo VI, verdaderas meditaciones que siguen los pasos de las antiguas exhortaciones de los Padres de la Iglesia en el estilo, señalan la oración personal y comunitaria como fuente de la promoción, invitan a los jóvenes al total seguimiento de Cristo subrayando la belleza y la plenitud humana de tal seguimiento, y ofrecen todo un compendio de exposición teológica sobre la vocación con la consiguiente llamada y propuesta vocacional.

Los documentos de Pablo VI sobre el tema, densos como todo su magisterio, están diseminados en numerosos discursos y documentos, como la encíclica Summi Dei Verbum (4.11.1963), que celebra el cuarto centenario del decreto del Concilio de Trento sobre los seminarios, invitando a las Conferencias Episcopales a adecuarlo a las situaciones de hoy. En dicha encíclica el Papa determina los criterios de discernimiento, admisión y renovación vocacional. A esta tarea son también llamados a cooperar los educadores y los institutos religiosos ${ }^{28}$. El Papa es ya consciente del desplome iniciado en los seminarios menores y la caída del número de vocaciones (aunque la crisis no había llegado aún con toda su fuerza), y señala la necesidad de renovar la pastoral vocacional y del compromiso de los educadores (padres y formadores) en los programas y métodos, señalando la oración como corazón de toda acción vocacional y las obras que de esta conciencia se derivan. Siguen las indicaciones de la Populorum progressio (1967),

28. Pablo VI, Summi Dei Verbum (4 de noviembre de 1963), AAS 55 (1963) 984ss. 
donde se señala la vida como vocación; la Evangelica testificatio (1971), sobre la vida religiosa y su misión; la Evangelii nuntiandi (1975), que presenta la vocación cristiana en sus dimensiones evangelizadora y misionera (EN 15, 18, 66-70). En la Populorum progressio, en el contexto magisterial de la vida como vocación encuentra espacio la propuesta del sacerdocio a los jóvenes y la indicación de Cristo sacerdote, que ofrece amistad y llama a seguirlo a los jóvenes de hoy hasta su ofrenda en la cruz. Pero desde los años de la Populorum progressio, la crisis social y eclesial alcanza ya de hecho a los seminarios, en especial a los menores, y al ministerio sacerdotal. Por esto la Sagrada Congregación para la Educación Católica publica una nota (23.5.1968) donde se subrayan algunos aspectos a propósito de las vocaciones de adolescentes y jóvenes al ministerio sacerdotal, y también sobre el valor de los seminarios menores, señalando también las dificultades en las familias y en el mundo de la escuela y la crisis de la institución educativa; el Documento habla de «paso de obra cerrada a referencia abierta, con adaptación a las circunstancias, con atención a las vocaciones adultas. Es necesaria la conexión, en unión de esfuerzo del servicio de las vocaciones, con la pastoral de la juventud, como centro de impulso generoso, articulado en relación con la edad creciente de los jóvenes. Algunos límites pasados ya no son soportables: un seminario mayor reducido, la separación por un contexto de pastoral integral». Ya un pontífice es conocedor de una situación agravada por la crisis que enfrenta sociedad e Iglesia. No sirven ya los «odres viejos para echar el vino nuevo», se podría decir. Pablo VI guía la Iglesia en los años que preparan la gran crisis del 68 y la continúan. Esta crisis se ha diluido rápidamente porque, entre otros, en su interior tiene poder el ala marxista-leninista. Acabado el movimiento, surgieron grupos bastante confusos y esa mentalidad que Benedicto XVI ha descrito en numerosas intervenciones. Ahora lo postmoderno se ha introducido en todos los ambientes de la vida, con un pesimismo cultural evidente en las formas descritas por el Papa y que Luigi Giussani, en una comunicación al Simposio internacional de la Congregación para el Clero del 1995, identificaba en cuatro desafíos: nihilismo, agnosticismo, guerra y cinismo, actitudes destinadas a acabar mal en la idea de cambiar el mundo, terminando fatalmente en una mentalidad de impotencia y de nueva barbarie no menos cruel que las del siglo breve de los totalitarismos, como se llama al siglo XX. Frente a esos retos se sugiere un método educativo conjugado en cuatro aspectos opuestos a cada una de las actitudes: la experiencia mística o del Misterio, la del Acontecimiento cristiano (es en el camino de Cristo donde el hombre reconoce su rostro y su destino de hijo) y la victoria final de la fe que parte a la conquista de lo real. En efecto, la dinámica cultural del acontecimiento cristiano nace de aquel «por quien se vive»; el hombre no vive para sí, como afirmación de sí, sino por «Aquel que murió y resucitó por él»².

29. L. Giussani, Comunicación al Simposio internacional de la Congregación para el Clero, en el XXX aniversario del decreto «Presbyterorum Ordinis», Roma 24 de octubre de 1995. 
Sin embargo, no todo ha sido negativo, porque a partir de esos años nacen en la Iglesia realidades positivas, como un mayor compromiso del mundo católico en la política, en el servicio social, en el voluntariado con numerosas asociaciones, también en el campo de la promoción humana y misionera, y sobre todo crecen los movimientos eclesiales con una clara autoconciencia cristiana, poniendo a Cristo en el centro de la historia, de la vida, y un relanzamiento de la presencia misionera activa en países extraeuropeos. Ciertamente la vieja Europa enferma parece caminar hacia un cada vez más agudo desgaste de sus antiguas raíces cristianas, pero eso no quita la esperanza de que tales movimientos reconduzcan hoy a la Iglesia y también al mundo Occidental ${ }^{30}$. Precisamente en estos años de desorientación en muchos, de esperanzas vivas en otros, el venerado Pablo VI es llamado a la vida eterna (6.8.1978), dejando el timón de la Iglesia a su sucesor de breve duración, el también amado Juan Pablo I, que tras solo un mes de pontificado pasa también a la vida eterna.

\section{Juan Pablo II}

El pontificado de san Juan Pablo II (1978-2005), con el numeroso bagaje de documentos producidos, los frecuentes viajes apostólicos y las relativas intervenciones en todo ámbito, también en el vocacional, requiere necesariamente un estudio específico, incluso en el tema vocacional. Solamente podemos ofrecer aquí algunos datos, casi estadísticos, sobre su magisterio vocacional. Juan Pablo II desde el primer día de su pontificado presenta a Cristo, Redentor del hombre, como centro de la historia y salvación de la humanidad. Además, el tema vocacional se inserta en esa Realidad que es Cristo. En un simple elenco, sus intervenciones sobre el tema vocacional y la formación sacerdotal y en la vida religiosa pueden ser agrupadas globalmente en diversos sectores:

a) Sus intervenciones magisteriales, por orden cronológico: Redemptor hominis (1979), Catechesi tradendae (1979), Familiaris consortio (1981), Código de Derecho Canónico (1983), Redemptoris Donum (1984), Christifideles laici (1988), Catecismo de la Iglesia católica (1992), Pastores dabo vobis (1992), Vita Consecrata (1996), Novo millenio adveniente (10.11.1994), Novo millenio ineunte (6.1. 2001), Ecclesia de Eucharistia (2003), Pastores gregis (2003).

b) Sínodos de Obispos. Los sínodos que periódicamente se celebran a partir del pontificado de Juan Pablo II suelen aportar indicaciones de carácter vocacional en general, sobre la vocación cristiana fundamental de los laicos, sobre el ministerio de los presbíteros y sobre la vida religiosa. Por ejemplo, el Sínodo de octubre de 1990 sobre «Formación de los sacerdotes en las circunstancias actuales» produce la documentación base para la Exhortación Apostólica Post-

30. Testimonio de esta realidad nueva son los movimientos eclesiales: Cf. F. González Fernández, Los movimientos. De la Iglesia de los apóstoles hasta hoy, Milano 2000. 
sinodal Pastores dabo vobis (1992), subrayando la urgencia de cuidar las vocaciones, en el contexto social y eclesial del momento. Insiste sobre el necesario acompañamiento vocacional, la conveniencia del seminario menor y de otras iniciativas para la promoción vocacional y el acompañamiento de las vocaciones y las líneas pedagógicas de la formación en los seminarios. El Sínodo de octubre de 1994 sobre la «Vida consagrada y su misión en la Iglesia y en el mundo», que dará origen a la Exhortación Apostólica Vita Consecrata (1996), da indicaciones precisas en la misma dirección, señalando dificultades y dando orientaciones para su superación de cara a un renovado compromiso en la vida religiosa.

c) Las Exhortaciones post-sinodales continentales, promulgadas después de cada Sínodo para tratar la problemática específica de cada continente, presentan, entre otros, temas y aspectos en las condiciones socio-religiosas de cada continente y que influyen o condicionan el tema de las vocaciones en relación a la evangelización. En cierto sentido, es la primera vez que tales problemáticas y perspectivas han sido tratadas en documentos eclesiásticos sinodales por parte de una Asamblea General estudiando los casos concretos de cada continente: Ecclesia in Africa (1995), Ecclesia in America (1999), Ecclesia in Asia (1999), Ecclesia in Oceania (2001), Ecclesia in Europa (2003).

d) Las Jornadas Mundiales de Oración por las Vocaciones: siguen el método inaugurado por Pablo VI en 1964; Juan Pablo II continúa ofreciendo un mensaje en el que da aclaraciones, directrices y profundiza en los temas vocacionales siguiendo ya las huellas de las anteriores jornadas: «a) orar, llamar, responder; b) los jóvenes son destinatarios privilegiados y los primeros interlocutores de las llamadas; c) la continuidad fiel a las enseñanzas del Concilio, eclesiología, teología bíblica, trinitaria, cristocéntrica, bautismal unitaria y articulada; d) los lugares pastorales del testimonio; catequesis, familia, escuela, propuesta y llamada, una verdadera cultura vocacional $»^{31}$. Cada jornada anual viene anunciada con un mensaje del Papa en el que, a lo largo de los años, podemos ver un magisterio catequético, teológico y pastoral sobre el tema ${ }^{32}$.

El Magisterio pontificio sobre el tema vocacional y la formación de los candidatos al sacerdocio y a la vida religiosa así como la naturaleza de estos dos estados de vida en la Iglesia es fecundo en estos años también a través de numerosos y diversos documentos publicados durante este tiempo:

e) Documentos de los dicasterios de la Curia Romana, como la Renovationis causam (1969) de la Congregación para los Religiosos e Institutos Seculares ${ }^{33}$; la Ratio Fundamentalis Institutionis Sacerdotalis (1970) de la Congregación para

31. P. Gianola, en DPV, 665; citado en Llanos, 67 ,

32. Congregación para la Educación Católica y Pontificia Obra para las Vocaciones eclesiásticas, Mensajes para la Jornada Mundial de Oración por las Vocaciones, Roma 1993. Los mensajes se pueden ver también en el sitio web del Vaticano.

33. Sagrada Congregación para los Religiosos y los Institutos Seculares, Instrucción Rennovationis Causam (6 de enero de 1969), AAS 61 (1969) 101-120. 
la Educación Católica, que trata de forma jurídica los puntos necesarios para la aplicación del decreto conciliar Optatam totius del Vaticano II.

En esta Ratio se expone la naturaleza de la vocación sacerdotal dentro de la vocación fundamental cristiana en el Pueblo de Dios (n. 5-19). La vocación es un don del Espíritu para construir la Iglesia en sus diversos ministerios, por los cuales la Iglesia debe ser promovida, cuidada y ayudada a madurar. La llamada vocacional dentro de la Iglesia para su servicio puede darse en toda edad, circunstancia y momento; así pues, corresponde a la Iglesia, o sea, a la comunidad cristiana, rogar por las vocaciones, verificarlas, examinar la intención de los llamados, su idoneidad y su libertad para acoger la vocación. En tal contexto es decisivo el testimonio de los sacerdotes, así como su deber de suscitar, promover y acompañar las vocaciones. Este documento hace referencia también a la tarea y el uso de las ciencias humanas (psicología, pedagogía y sociología) en el campo vocacional. También subraya la necesidad de crear ambientes idóneos, entre estos el seminario menor, para el cuidado de las vocaciones y su formación, y también el papel de todas aquellas instituciones que tienen un puesto fundamental en la vida de la Iglesia como en otros, tales como la familia, la parroquia, y aquellas realidades eclesiales y sociales que ayuden al nacimiento, crecimiento y madurez de las vocaciones. En este sentido se subraya también la importancia de la verificación vocacional y de un verdadero discernimiento y selección de las vocaciones a la luz de cuanto se ha indicado más arriba.

Por su parte, la Congregación para la Educación Católica publica en 1977 el documento La Escuela católica. En él da indicaciones de carácter educativo que tocan también lo vocacional. La escuela católica como ámbito educativo «se caracteriza por la comunicación crítica y sistemática de la cultura en orden a la formación integral de la persona», persigue tal fin en la visión cristiana de la realidad «mediante la cual la cultura adquiere su lugar privilegiado en la vocación integral del hombre». Teniendo en cuenta que el hombre histórico es el hombre redimido por Cristo, «la escuela católica trata de formar al cristiano en la virtud que lo habilita para la vida nueva en Cristo, permitiéndole colaborar en fidelidad a la edificación del reino de Dios» (n. 36) ${ }^{34}$. En este contexto se confirma la relevancia de la enseñanza de la religión en la escuela: «La enseñanza de la doctrina evangélica como se transmite por la Iglesia católica. Éste es, en efecto, el elemento fundamental de la acción educativa, destinado a orientar al alumno hacia una elección consciente, viviéndola con empeño y coherencia» (n. 49).

En estos años, muchas Conferencias Episcopales publican orientaciones y normas para la promoción y formación sacerdotal, aprobadas por la Congregación para la Educación Católica, y en el caso de las Conferencias bajo la jurisdicción de la CEP (Congregación para la Evangelización de los Pueblos) también

34. Sagrada Congregación para la Educación Católica, Carta La Escuela Católica (24 de junio de 1977): EV (1977-1979), 60-119. 
con el examen de parte del Dicasterio misionero; lo mismo hacen normalmente muchos Institutos religiosos para los propios miembros ${ }^{35}$.

En estos años, precisamente, se reaviva el debate sobre la libertad de enseñanza, frente a la política controladora y monopolística de muchos Estados, que coarta o limita iniciativas privadas, entre las que se hallan las promovidas por la Iglesia (diócesis, órdenes religiosas...). Por otro lado, en muchos Estados se discute el tema de la presencia de la enseñanza religiosa en las escuelas públicas, al comprender erróneamente la laicidad del Estado y, por ello mismo, de la escuela pública. Pero también las propuestas educativas en el campo católico se hacen cada vez más vivas, con numerosas iniciativas en el campo educativo (escuelas) y ante todo en el debate sobre la educación. Aquí destaca la propuesta del gran pedagogo y sacerdote italiano Luigi Giussani, el cual trabajó intensamente por proclamar «el anuncio cristiano como algo totalmente nuevo, absolutamente original, y de transmitirlo de forma que conmueve sobre todo los corazones de los jóvenes. Los conmueve según una modalidad hoy rara: pidiéndoles una decisión, la de concebir toda su vida como un encuentro con Jesucristo en la Iglesia de hoy [...]. Vivimos en una época en la que el cristianismo ha 'palidecido' de manera singular. Se mueve sobre huellas que son ricas en 'tradiciones', pero al mismo tiempo 'tradicionales', y se le percibe como en algún modo restrictivo». En este contexto, la misión educativa y la propuesta vocacional se hace necesaria y urgente, porque el cristiano con esta autoconciencia está llamado a convertir al mundo y lo que es del mundo, incluso a aquel que en esto está lejos de Dios, en transparente para Cristo: mostrar lo que preocupa al hombre de hoy y que esas preocupaciones encuentran una respuesta plena sólo en Cristo, para quien todo aspecto, aun los aparentemente más contradictorios, es una invitación a hablar del camino al que el Señor nos llama a seguirle. «Convertir el mundo en transparente para Cristo, mostrar que esto es posible, que hasta lo que en la cultura de hoy hay de más anómalo y desviado puede ser un camino que conduce a Él». Lo que no es admisible es solamente la superficial inautenticidad, «nuestro ser obstinadamente testarudo, la pereza espiritual que nos impide mirar de cara a la realidad ${ }^{36}$, porque educar conlleva «introducir en la realidad total: abandonarse a Cristo quiere decir experimentar sus dimensiones, la primera de las cuales es que Cristo es la realidad que explica todo [...]; la segunda dimensión significa darse cuenta de que ser cristiano es convivir y compartir: [esto es] la caridad [...]; experimentar la tercera dimensión significa darse cuenta de que ser cristiano es convivir y compartir sin medida; [...] he aquí el deseo misionero; ser cristianos significa aceptar una misión sin límites. La atracción humana del cristianismo se traduce de modo más completo en esta palabra: 'misión'» ${ }^{37}$.

35. Así la Conferenza Episcopale Italiana, La formazione dei Presbiteri nella Chiesa Italiana. Orientamenti e norme (15 agosto 1972), Roma 1972.

36. N. Lobkowicz, Prólogo a L. Giussani, II rischio educativo, Torino 1995, VII-XI.

37. L. Giussani, II rischio educativo, 103-107. 


\section{Ratio fundamentalis}

En este contexto, las diócesis y los institutos religiosos inician un trabajo que obliga a formular una ratio formationis vocacional y de formación sacerdotal o religiosa adecuada a las propias realidades. Nacen además planes pastorales diocesanos o de órdenes religiosas en el campo de la promoción vocacional. Fue de nuevo la Congregación para la Educación Católica la que en 1978 publicó un documento donde presenta los elementos clave (doctrinales, espirituales, organizativos) de la promoción vocacional en los planes pastorales diocesanos y propone un plan operativo ${ }^{38}$. Entre estos elementos indica algunos: situación local, búsqueda de las causas internas y externas de la situación, reflexión teológica sobre la Iglesia particular en orden a las vocaciones (misión de la Iglesia local), responsables de la promoción y formación vocacional, medios necesarios para tal fin (anuncio, liturgia y oración, educación, la obra de las vocaciones).

\section{En el campo de la vida religiosa}

Las congregaciones vaticanas para los religiosos (CRIS) ${ }^{39}$ y la de los obispos publican en 1978 un documento capital para el tema: Mutuae relationes ${ }^{40}$. Se dice en su introducción: «Las dos Congregaciones, para los Obispos y para los Religiosos y los Institutos Seculares, en el décimo año de la promulgación de los decretos Christus Dominus y Perfectae caritatis (28.10.1965), han celebrado una asamblea plenaria mixta (16-18.10.1975) con la consulta y colaboración de las Conferencias Nacionales de Obispos, de las Uniones Nacionales de Religiosos, además de las Uniones Internacionales de Superiores y Superioras generales. En esta Asamblea plenaria se afrontaron, como temas principales, las siguientes cuestiones: a) qué esperan los Obispos de los religiosos; b) qué los religiosos de los Obispos; c) con qué medios se puede en la práctica conseguir una ordenada y fecunda acción entre los Obispos y los religiosos tanto en el plano diocesano como en el nacional».

38. Sagrada Congregación para la Educación Católica, Los planes pastorales diocesanos para las vocaciones (2 de enero de 1978): EV (1977-1979) 404-420.

39. El Dicasterio ha cambiado desde que Sixto V creó la Congregatio super consultationibus regularium (1586) confirmada por la Constitución Inmensa (1588), y unida a la Congregatio pro consultationibus episcoporum et aliorum praelatorum (1601). Pío X, con la Costitución Sapienti Consilio (1908), separó de nuevo ambas instituciones; sometió la de Obispos a la Consistorial y dejó autónoma la Congregación de Religiosos. Con la Constitución Regimini Ecclesiae Universae (1967) de Pablo VI, la Congregación de Religiosos se denomina Congregación para los Religiosos e Institutos Seculares. La Constitución Pastor Bonus (1988) de Juan Pablo II la denomina Congregación para los Institutos de Vida Consagrada y Sociedades de Vida Apostólica (CIVCSVA): se ocupa de cuanto atañe a Órdenes, Congregaciones, Institutos seculares, Sociedades de vida apostólica, vida eremítica, virgenes consagradas y nuevas formas de vida consagrada; algunas cuestiones son, no obstante, competencia de otras Congregaciones. Cf. Annuario Pontificio, Città del Vaticano 2009, 1894-1895.

40. Congregación para los religiosos y los institutos seculares - Congregación para los Obispos, Notas directivas Mutuae relationes (14 mayo 1978): EV 6 (1977-1979) 432-509. 
El documento señala también las modalidades de esta coordinación en la pastoral dentro de la Iglesia; el sentido del antiguo concepto y praxis de la exención de los religiosos como salvaguarda de la propia identidad carismática al servicio de la Iglesia; el servicio eclesial de los religiosos y su obediencia y adhesión al Papa y a los Obispos, ofreciendo en comunión «el específico testimonio y la genuina misión de su Instituto; en fin estimularán siempre la sensibilidad e interdependencia de apostolado, que son características de su consagración» (n. 22). El documento señala además criterios de inserción pastoral de los religiosos y de la formación en el contexto local donde trabajan (n. 23). Recoge un hecho importante: el nacimiento de nuevos institutos y realidades carismáticas y la necesidad de un discernimiento de estas iniciativas, «buscando intuir con garantía las perspectivas de futuro y todo indicio relativo a una creíble presencia del Espíritu Santo, 'ya para acoger los carismas... con gratitud y agrado' (LG 12) ya para evitar 'que incautamente surjan institutos inútiles o desprovistos del suficiente vigor' (PC 19). En efecto, cuando el juicio sobre el nacimiento de un Instituto se formula sólo en vistas a su utilidad y competencia operativa o simplemente al modo de actuar de alguna persona, que experimenta fenómenos devocionales por sí mismo ambiguos, entonces en verdad demuestra que queda en cierto modo deformado el genuino concepto de vida religiosa en la Iglesia». Los criterios sobre nuevos Institutos y realidades carismáticas ofrecidos en el documento son además de enorme y actual importancia: «a) una singular proveniencia del Espíritu, distinta, aunque no separada, de las peculiares dotes personales, que se manifiestan en el campo operativo y organizativo; b) un profundo ardor de ánimo por configurarse a Cristo para testimoniar algún aspecto de su misterio; c) un amor constructivo a la Iglesia, que absolutamente rehúye provocar en ella cualquier discordia». Indica también los criterios principales para juzgar a los nuevos fundadores: virtud probada, docilidad eclesial, y aceptación por su parte de un prudente juicio de quienes tienen responsabilidad en la materia (n. 51).

En 1978 la Congregación para los religiosos e Institutos Seculares publica otro documento titulado Religiosos y promoción humana ${ }^{41}$. El documento aborda las diversas y problemáticas posiciones existentes en la Iglesia de cara a afrontar los agudos problemas del subdesarrollo de muchos pueblos, de las injusticias sociales y de la pobreza. El documento vio la luz tras la sesión plenaria del 25 al 28 de abril de 1978. En él ofrece un análisis de las dificultades concretas (situaciones, iniciativas, compromiso social) y refiere la intensa actividad de los religiosos en el campo social, vinculadas al tema de la evangelización; señala las modalidades de inserción y los desafíos correspondientes, y habla también del compromiso en el mundo de la política y las condiciones que deben darse para evitar toda implicación directa en la praxis política. A los religiosos se les exige

41. Congregación para los institutos de vida consagrada y sociedades de vida apostólica, Religiosos y promoción humana, Plenaria SCRIS (25-28 abril 1978). 
sobre todo testimonio y obras donde se hagan creíbles «expertos del Evangelio» en la construcción de la sociedad. La participación política activa será un acto de suplencia según exigencias y situaciones especiales a evaluar. En este marco se señalan los criterios para un discernimiento vocacional que son: la fidelidad al hombre, a Cristo y a la Iglesia, y al carisma del propio Instituto. Todo esto tiene consecuencias en el plan formativo de los religiosos con «una educación profunda, de mentalidad y de estilo de vida, que haga capaces de permanecer ellos mismo aunque en nuevos modos de presencia. Presencia siempre de 'consagrados', que orienten con el testimonio y las obras, la trasformación de las personas y de la sociedad en la dirección del Evangelio» (n. 32). El Documento alude después a los «nuevos contextos de inserción», a los «nuevos problemas» que crean «situaciones imprevistas» y que por eso exigen una preparación espiritual y humana específica de los religiosos implicados en ellas, siempre en comunión con la Iglesia. Capítulos generales y Dirección de los Institutos deberán, pues, estar atentos a estas situaciones, exigencias y propuestas formativas (cf. 33). Es innegable el decisivo influjo de este y otros documentos en la formación de los religiosos, en estos momentos tan convulsos y delicados.

También la misma Congregación (CRIS) en su Plenaria de marzo de 1980 estudió la dimensión contemplativa de la vida religiosa en continuación con la Plenaria de $1976^{42}$. Si ya se había señalado el lugar de los religiosos en la promoción integral del hombre, incluso en sus aspectos socio-políticos, ahora se resalta «la importancia fundamental de la interioridad espiritual de toda forma de vida consagrada» y se advierte "la necesidad y urgencia de resaltar el absoluto primado de la vida en el Espíritu Santo» (Introducción). Aunque aquí el Documento reconoce el aumento de inciativas en la Iglesia en el campo religioso contemplativo y los intentos de «superar la nociva dicotomía entre interioridad y actividad en la vida personal y comunitaria de los religiosos y las religiosas, en relación a cierto periodo de devaluación de la oración y el recogimiento, no del todo superado aún» (Introducción). Por eso este nuevo Documento se divide en tres partes que en sí mismas son esclarecedoras: 1) Descripción de la dimensión contemplativa; 2) Orientaciones para los Institutos de vida activa; 3) Orientaciones para los Institutos contemplativos. Lógicamente estas normas tocan las orientaciones formativas en la vida religiosa, dado que esa dimensión envuelve toda la existencia, y esto desde las primeras etapas de orientación vocacional y de formación en la vida religiosa. La dimensión contemplativa se señala también como fuente y punto esencial en el trabajo de renovación de los Institutos religiosos. Como ya había indicado Juan Pablo Il en su discurso de 24 de noviembre de 1978 y recordado en el n. 30 de este Documento: «Vuestras casas deben ser sobre todo centros de oración, de recogimiento, de diálogo -personal y sobre todo

42. Congregación para los Institutos de Vida Consagrada y Sociedades de Vida Apostólica, La dimensione contemplativa della vita religiosa, Plenaria SCRIS (4-7 marzo 1980). 
comunitario- con Aquel que es y debe ser el Primero y Principal interlocutor en el activo transcurrir de vuestra jornada». Las consecuencias para la promoción vocacional y la formación son por eso evidentes.

En 1983, a los veinte años de la renovación conciliar, la Congregación publica un nuevo documento ${ }^{43}$ en el que, tras reconocer los pasos dados en ese sentido y la problemática verificada en el seno de la comunidad religiosa debido a factores sociales y eclesiales (internos y externos), la crisis vocacional, la incertidumbre respecto a la propia identidad en algunos religiosos, reconoce cómo estos factores están provocando una situación compleja con sus correspondientes problemas (cf. 1), por lo cual la renovación pide también una verificación de las iniciativas en curso (cf. 2). En este sentido la Congregación publica el documento donde se recogen principios y normas fundamentales intentando ofrecer una síntesis clara de la en señanza de la Iglesia sobre la vida religiosa (cf. 2).

Cronológicamente sigue otro importante documento, éste de la Congregación para la Educación Católica en 1988 sobre la dimensión religiosa de la educación en la escuela católica. Retoma antiguos temas reavivados en las últimas décadas del siglo XX. Replantea el tema educativo, estudia el lugar de la enseñanza de la religión en la escuela y globalmente la colocación de la dimensión religiosa en el proceso educativo. En el campo vocacional, aunque el documento no trata directamente el tema, se entiende la importancia de las indicaciones dadas en tal apartado, en especial de cara al educador mismo y a la educación como transmisión de una experiencia: la de la fe cristiana, sobre todo por parte de los educadores laicos. La transmisión de la antropología cristiana en el marco de la historia de la salvación a los estudiantes tiene un valor educativo de enorme alcance (cf. 76); lo mismo vale para la transmisión de la catequesis sacramental y su comprensión (cf. 79), y de los valores naturalmente cristianos así como las indicaciones de los contravalores humanos y por eso no cristianos (cf. 87). Esta educación prepara al joven para acoger la vocación que Dios le da en la vida y pone así en el sitio justo y valora la educación en el sentido religioso.

Ya en 1990, la misma Congregacion publica un nuevo documento dando directrices sobre la formación en los Institutos Religiosos ${ }^{44}$ y en 1993 la Congregación para La Educación Católica publica otro documento sobre la preparación de los educadores en los Seminarios ${ }^{45}$. De nuevo en 1994, publica otro documento sobre la vida fraterna en comunidad ${ }^{46}$. Se llega así a 1998 con la publicación de

43. Id., La vida religiosa en la enseñanza de la Iglesia: sus elementos esenciales en los institutos dedicados a obras de apostolado, Città del Vaticano 1983.

44. Id., Directrices sobre la formación en los institutos religiosos Potissimum institutioni (2 febrero 1990): EV 12 (1992) 1-139.

45. Congregación para la Educación Católica de los Seminarios y los Institutos de estudio, Directrices entre los varios medios sobre preparación de los educadores en los Seminarios (4 noviembre 1993): EV 13 (1991-1993) 1734-1775.

46. Congregación para los Institutos de Vida Consagrada y Sociedades de Vida Apostólica, La vida fraterna en comunidad (2 de febrero de 1994): EV 14 (1994-1995) 220-283. 
la Ratio fundamentalis institutionis diaconorum permanentium. Directorio para el ministerio y vida de los diáconos permanentes. En el mismo año 1998 la Congregación promulga una nueva Instrucción considerando la colaboración entre Institutos en la formación de sus miembros en las circunstancias actuales. También en 1998 la Congregación para la Educación Católica trata en un nuevo documento informativo sobre la situación del Periodo Propedéutico en preparación a la entrada en el seminario Mayor de los candidatos al sacerdocio, en la línea señalada en Pastores dabo Vobis en el n. 662 ${ }^{47}$. En 1999, de nuevo publica otro documento, Verbi Sponsa, sobre la vida contemplativa y la clausura de las monjas $^{48}$. Ya en el 2002, la Congregación publica un nuevo documento, proponiendo esta vez un renovado compromiso de la vida consagrada en el tercer milenio; en éste en los números 16 a 18 habla precisamente de la animación vocacional y los procesos formativos ${ }^{49}$. En el mismo años 2002 la Congregación para la Educación Católica retoma de nuevo el preocupante tema de la educación, vista la situación de deterioro social como el proceso de secularización, la crisis vocacional, las defecciones en la vida sacerdotal y religiosa, la desafección a la misión educativa en las escuelas por parte de muchos sectores y antiguas instituciones educativas en la misma Iglesia. Por lo cual el Dicasterio afronta la problemática y recuerda los deberes educativos de los educadores católicos y el compromiso misionero no cedible de los cristianos en este campo.

En los primeros años del Tercer Milenio estalla con fuerza cada vez más agresiva en los Medios de comunicación social de todo el mundo la temática de los abusos a menores (pedofilia) en algunos países por parte de algunos miembros del clero secular y regular. En tal contexto frente a las fuertes acusaciones cada vez más graves, iniciando en los Estados Unidos de América y que rápidamente se extiende a otros países del mundo, tanto cada una de las conferencias episcopales como la Santa Sede interviene con diversos documentos, progresivamente cada vez más numerosos y frecuentes en los años siguentes. Uno significativo es el titulado Recognitio de la Santa Sede para las «Essential Norms» del $2002^{50}$. Estas dolorosas y lamentables situaciones tendrán consecuencias claras y específicamente señaladas de parte de la Santa Sede en el

47. Congregación para la Educación Católica de los Seminarios y de los Institutos de estudio. El perído Propedéutico. Documento informativo, Città del Vaticano 1998.

48. Congregación para los institutos de vida consagrada y sociedades de vida apostólica, Instrucción Verbi Sponsa sobre la vida contemplativa y la clausura de las monjas (13 de mayo de 1999): EV 18 (1999) 516-577.

49. Congregación para los institutos de vida consagrada y sociedades de vida apostólica, Instrucción sobre el renovado compromiso de la vida consagrada en el tercer milenio Ripartire da Cristo (19 mayo 2002), Città del Vaticano 2002.

50. Congregación para los Obispos, Decreto Recognitio of the Holy See for the essential Norms approved by the United States Conference of Catholic Bishops (8 december 2002). También: Canonical Delicts Involving Sexual Misconduct and Dismissal from the Clerical State, 1995; Letter from the Congregation for the Doctrine of the Faith (18 mayo 2001); Procedural Norms for «Motu Proprio» Sacramentorum sanctitatis tutela: AAS 93 (2001) 787. 
tema del discernimiento vocacional y de la formación al sacerdocio y a la vida religiosa. En 2004 la Congregación de Obispos, publica el documento Apostolorum Successores, Directorio para el ministerio pastoral de los Obispos ${ }^{51}$, donde se encuentra un amplio tratado sobre la espiritualidad y la formación del mismo obispo, y por tanto de su responsabilidad en el campo vocacional (cf. 91).

De este largo elenco de documentos sólo se puede decir que jamás en la historia de la Iglesia los organismos eclesiásticos a todos los niveles han producido una cantidad similar de documentos con toda la problemática de un atento estudio de ellos y puesta en práctica, a menudo incluso olvidada.

\section{La Pontificia Obra para las Vocaciones Eclesiásticas}

Al comenzar el tercer milenio, el problema vocacional y el de la formación de los ministros de la Iglesia ha sido y es sentido como prioritario en muchas intervenciones, directrices y documentos del Magisterio Pontificio y de los Organismos vaticanos o de algunos a nivel nacional en diversos países. Entre ellos destaca, como propio de su misión, los provenientes de la Educación Católica y los de la Congregación de Religiosos ${ }^{52}$. En el caso de la primera hay que señalar la Pontificia Obra para las Vocaciones Eclesiásticas con varias fases, las perspectivas para la promoción vocacional del inicio del tercer milenio. Estos cambios han influido en la temática vocacional dentro de la Iglesia a todos los niveles: desde el mismo concepto hasta la aplicación en el campo de la promoción vocacional, el discernimiento, la formación y la delicada misión de los educadores. Entre los aspectos señalados en dicha obra resaltamos estos ${ }^{53}$ :

a) La búsqueda de autenticidad vocacional;

b) La superación de la promoción vocacional de emergencia;

c) La abundancia de documentos referentes al tema vocacional, salidos de la autoridad y magisterio eclesiástico; estos documentos invitan a una continua reflexión y al discernimiento y criba de vocaciones, con el descubrimiento de signos negativos, como la crisis profunda de las personas e instituciones, la falta de significatividad de los modelos y la existencia de un cambio de calidad, el redescubrimiento de algunos aspectos metodológicos del pasado, también en la animación vocacional, y la aplicación de los principios de una sana psicología y de las ciencias humanas en el campo pastoral.

51. Congregacón para los Obispos, Directorio para el Ministerio Pastoral de los Obispos "Apostolorum successores», Città del Vaticano 2004.

52. Cf. Llanos, 100-116: con cuadros de carácter estadístico donde se indican los destinatarios, el tema, y las conclusiones. También R. Sacco, Congresos internacionales sobre las vocaciones de «especial» consagración, en DPV, 270.

53. Llanos, 117-127; en el resto de su obra analizada ofrece perspectivas del tema vocacional en sus diversos aspectos (teología, pastoral y psicología) (129-462). G. Bosco, Vocación: educar a un proyecto de vida, en B. Bosco (ed.), Giovani e vocazioni, Proposte di pastorale giovanile 6, Leumann, Torino 1993, 92-99; A. Cencini, Vocaciones de la nostalgia a la profecía. Salamanca 2007, 41-52. 
d) Una fundamentación teológica a la luz de las enseñanzas del Vaticano II (siguiendo Lumen gentium y otros textos conciliares, como: el lugar de la Palabra de Dios, los aspectos cristológicos, mariológico, eclesiológicos; el puesto de los valores y factores humanos, y además la recuperación del sentido de lo humano, como aspecto esencial frente a una negación de la humanidad o una acentuación exasperada de aspectos subjetivos o reductores de la misma, apelándose incluso con frecuencia a un uso parcial de las ciencias humanas o a teorías filosóficas y psicológicas discutibles. De aquí la necesidad de una atención a todos estos nuevos elementos y situaciones, para evitar por una parte limitarse a considerar únicamente la prioridad de la institución vocacional y de los valores objetivos de la misma, para pasar a la exaltación del sujeto y de sus cualidades, como elementos fundamentales en el discernimiento vocacional, lo que Llanos llama «idolatría del yo» ${ }^{54}$. De aquí la necesidad de una integración entre los dos extremos.

e) Otro aspecto indicado es la comprensión de la mediación eclesial, dado que la vocación viene de Dios a través de la mediación de la Iglesia.

f) Otro aspecto es el de la comunidad en cuanto sujeto y lugar de la promoción vocacional, subrayando de esta forma la intrínseca dimensión comunitaria de la promoción vocacional.

g) Una atención especial merecen las vocaciones específicas, también dentro de la realidad eclesial.

h) Por lo que se habla también de un «proyecto vocacional, personal e inculturado», descubriendo la vocación de cada uno, dentro de la realidad eclesial, y en el contexto social y eclesial donde se da y crece esta llamada, y en tal cuidado ténganse presentes las dimensiones educativas correspondientes; y aquí entra el rol y tarea de educador, no sólo a la hora de ayudar en el discernimiento, sino tambien en el ofrecimiento vocacional y en la formación correspondiente.

i) Lo cual requiere un nuevo estilo de animación vocacional.

j) Y también que el animador vocacional y el formador tengan una clara identidad y den testimonio en ella de la propia vocación.

k) El último elemento que se debería señalar es la exigencia de una precisa espiritualidad o experiencia de vida cristiana como de la oración, que está en el origen de toda vocación, la sostiene y la renueva, en cuanto la vocación es siempre una gracia de Dios: de aquí nace la necesidad también de una experiencia vocacional donde la experiencia de comunión y la dimensión misionera son aspectos inherentes en el tema vocacional en la vida cristiana y también en la vida de la Iglesia. Los problemas inherentes y abiertos, las nuevas comprensiones y las tareas en el campo vocacional en la vida de la Iglesia son hoy aún muchos y con numerosas ventanas abiertas, por el cambio social y epocal en curso, pero también por los fermentos eclesiales hoy muy vivos ${ }^{55}$.

54. Llanos, 120.

55. Llanos, 125-126. 
Queremos añadir también otra serie de factores y elementos que nos parecen fundamentales en la perspectiva vocacional de hoy en la vida de la Iglesia y que atañen a la cristología, la eclesiología, el derecho, y la realidad de los nuevos movimientos y comunidades cristianas así como las nuevas situaciones dentro de la vida de la Iglesia, que van de la catequesis a la liturgia, el ecumenismo, el diálogo inter-religioso, la preocupación por situaciones de frontera.

\section{Los mensajes para las jornadas mundiales de oración por las vocaciones y otros documentos pontificios sobre la vocación}

Benedicto XV, con la Carta Apostólica Maximum illud (30.11.1919) inicia la serie de intervenciones pontificias solemnes sobre el tema misionero, donde se afrontan también aspectos vocacionales en la vida de la Iglesia relacionados con su dimensión misionera. Es necesario recordar las numerosas intervenciones de Pío XI donde toca la temática, como las encíclicas Ad Catholici Sacerdotii (20.12.1935); Casti Connubii (31.12.1930); Rerum Ecclesiae (28.2.1926); Studiorum Ducem (sobre Tomás de Aquino y el estudio teólogico; 29.6.1923). También Pío XII en sus encíclicas misioneras: Evangelii Praecones (2.6.1951) y Fidei Donum (21.4.1957), u otras intervenciones suyas sobre la vida sacramental, la vida y formación sacerdotal y religiosa como Mediator Dei (20.11.1947), Mystici Corporis (29.6.1943), Sacra Virginitas (25.3.1954) determinan nuevos pasos en el Magisterio respecto a las vocaciones y al estado de vida sacerdotal y religioso. El beato Juan XXIII inicia una serie de mensajes para la Jornada Misionera Mundial (22.10.1960). A él se deben dos grandes encíclicas, la Princeps Pastorum (28.11.1959) sobre misiones católicas ${ }^{56}$, y Sacerdotii Nostri Primordia (1.8.1959) sobre el sacerdocio, en el Centenario del piísimo tránsito del Santo Cura de Ars.

Con Pablo VI se inician las celebraciones de la Jornada Mundial de Oración por las Vocaciones, desde la primera (11 de abril de 1964), a la XV (10 de abril de 1978). También todos los años de su pontificado manda un mensaje especial con motivo de la Jornada Misionera Mundial, desde 1963 hasta 1978 (no existen la de 1964, en pleno Concilio Vaticano II, ni la del año de su Encíclica Ecclesiam Suam, el 6 agosto 1964). Las continuará Juan Pablo II; durante su pontificado se han celebrado las jornadas desde la XVI a la XLII (1979-2005) mandando un mensaje que desarrolla un tema específico para cada jornada. Mensajes con contenido específico vocacional son también sus mensajes anuales con motivo de la Jornada Misionera Mundial; la Jornada Mundial de la Vida Consagrada, la Jornada Mundial de la Juventud. Por su parte Benedicto XVI continúa esa gran tradición con mensajes y numerosas intervenciones anuales y periódicas con motivo de la Jornada Mundial de las Vocaciones y la Jornada Mundial de la Juventud.

56. Juan XXIII, Encíclica Princeps Pastorum (28 noviembre 1959): AAS 51 (1959) 833-864. 


\section{Un recorrido reflejado también en el Derecho Canónico actual}

El recorrido descrito ha tenido su reflejo en la legislación de la Iglesia, sobre todo en el Código de Derecho Canónico (CIC). En la historia de la reforma de las instituciones eclesiásticas (derecho y curia romana) como las de 1583, 1908, 1967, 1917, 1983, han sido normalmente un punto de llegada, pero también de partida, con sus repercusiones en puntos esenciales de la vida de la Iglesia, como el sacerdocio sacramental y el aspecto carismático de la vida consagrada; en este sentido, como la historia, camina en la reforma y cambio de las instituciones de derecho positivo más serias según los tiempos, lo mismo las formas accidentales de sus expresiones y la formación y configuración de sus miembros. Uno de los hitos en este camino de renovación (la ley canónica se orienta siempre a defender a la persona, al sacramento, al carisma) ha sido el Código de 1917 y el de 198357, que no es una actualización del de 1917, sino una creación nueva: distribución diversa de la materia (con el abandono de la división en cinco libros, que pasan a ocho) y una respuesta a las necesidades de los tiempos. El código de 1917 era sustancialmente una distribución orgánica de leyes existentes, con la supresión de repeticiones y anacronismos. En muchos casos constituía un compromiso entre diversas tendencias. El Código de 1983 simplifica aspectos ya anacrónicos, como el viejo instituto del «beneficio». Todavía, hablando de los eclesiásticos, el Código de 1917 defendía aún como pricipio el foro eclesiástico (fuente de innumerables controversias entre Iglesia y Estado en la historia de la Iglesia), pero se admitían las excepciones establecidas en los Concordatos. En el 1983 de estos privilegios no se habla más. Nos hallamos ante una diferente eclesiología y ante situaciones históricas muy diversas. También respecto a los Obispos, en 1983 se les reconoce mayor autoridad: las facultades un tiempo concedidas cada cinco años por la Santa Sede son ahora facultades ordinarias contenidas en la misma potestad ordinaria de los obispos, y se les reconoce mayor autoridad sobre los párrocos, superando el principio de inamovilidad de los párrocos en ciertas parroquias (can. 454 del 1917; en el código de 1983 se habla sólo de «estabilidad», can. 522). Sobre los religiosos: ya en 1917 los de votos simples eran considerados verdaderos religiosos, confirmando la Conditae a Christo de 1900. En 1983: no se admite ya la identificación entre vida religiosa y consagración: la vida consagrada es un género, cuyos elementos teológicos sustanciales vienen bien definidos (c. 573.1) y los canónicos (c. 573. 2), que comprende dos especies, la vida religiosa y los institutos seculares, con posibilidad de nuevas formas de vida consagrada (c. 605), un tema muy discutido todavía hoy, y muchas realidades de vida consagrada se refieren al Pontificium Consilium de Laicis y no

57. Cf. la Constitución Apostólica Sacrae disciplinae leges, de 25 de enero de 1983; también el Prefacio del Código. J. Beyer, Le nouveau code de droit canonique. Espirit et structures : Nouvelle Revue Théologique 106 (1984) 360-382, 566-583; El código del Concilio Vaticano II. Del concilio al código, Bologna 1984. 
a la Congregación de Religiosos. Y aquí se incluye otra novedad importante: la realidad y pluralidad de carismas en la vida de la Iglesia (en la práctica el tema de los movimientos eclesiales). El código de 1983 deja muchas puertas abiertas y la base para su reconocimiento y protección jurídica, superando la tendencia a la uniformidad. Se defiende la autonomía de los institutos aprobados, incluidos los de derecho diocesano, en lo que se refiere a la vida interna y al gobierno. Aquí se inserta la temática del laico bautizado en la vida de la Iglesia y su derecho a constituir asociaciones eclesiales. En 1917 se hablaba en el título XVIII, pero de manera reducida y en referencia a las asociaciones de fieles en general (Terceras ódenes seglares, Cofradías, Pías uniones). En 1983: se les reconocen ministerios y oficios, también con ejercicio de la potestad de gobierno y es la apertura para la temática indicada de los movimientos en la vida de la Iglesia ${ }^{58}$.

La concepción eclesiológica sobreetendida es diversa. En síntesis, nos encontramos frente a una problemática histórico-teológica de fondo un tanto diversa: el códico de 1917 expresaba la teologia y sobre todo la eclesiología prevalente en aquel momento, que reflejaba la del Vaticano I, enseñada en los Seminarios en los textos escolásticos de eclesiología del tiempo. El código de 1983 se ve en cierto sentido la teología y la eclesiología del Vaticano II. En definitiva, Juan Pablo II en un discurso suyo (21 noviembre 1983) afirmaba que el código era el último documento conciliar ${ }^{59}$. La misma idea se contiene en la constitución apostólica Sacrae disciplinae leges, previa al código. Especialmente el libro II, De populo Dei, que refleja la visión típica de la Lumen Gentium: el libro está dividido en tres partes, De Christifidelibus, De Ecclesiae constitutione hierarchica, (De suprema Ecclesiae auctoritate, De Ecclesiis particularibus), De institutis vitae consecratae et de societatibus vitae apostolicae. He aquí, pues, como en definitiva el Código de 1983 es sí un punto de llegada, pero también uno de partida en su aplicación, determinada en la eclesiología, y también en la fisonomía del sacerdote y del religioso. El nuevo código busca después, a diferencia del viejo, señalar los fundamentos teológicos de las normas, expresar aquello que en términos técnicos se llama la «ratio legis» (no necesariamente una motivación humana). Cierto el código constituye la encarnación de un espíritu (como las reglas de un instituto religioso, que pueden no obstante evolucionar). Y esto supone siempre un proceso con sus límites y sus riesgos. Lo cual no quiere decir que lo real trascienda el ideal. El riesgo es otro: el código de 1983 codifica, tiende a dar forma estable a institutos que aún están en sus primeros pasos, los consejos pastorales y presbiterales y el sínodo de los obispos: Esto comporta ventajas, por la perspectiva de cara al futuro, y riesgos, por el peligro de una cristalización de instituciones de las cuales sólo tras cierta experiencia se podrá definir la forma apropiada. Pero precisamente este riesgo aceptado

58. Cf. en el de 1917 can. 1342 y 2, y en el de 1983 can. 230 y 3, y los can. 224-231.

59. L'Osservatore Romano, 21-22 noviembre 1983. 
conscientemente muestra el sincero esfuerzo por mantenerse fieles a las perspecivas abiertas por el Vaticano II. Por otra parte otras realidades eclesiales, nacidas recientemente deberán encontrar en un futuro su situación precisa en el ámbito del Derecho de la Iglesia.

\section{LOS MOVIMIENTOS LAICALES Y LA VOCACIÓN CRISTIANA BAUTISMAL ${ }^{60}$}

A lo largo de los dos últimos siglos de historia de la teología se ha dado una precisa reflexión teológica sobre la Iglesia Misterio de Comunión; basta recordar la contribución en este sentido de grandes teólogos del siglo XIX como Johan Adam Möhler (1796-1838) y el fecundo John H. Newman (1801-1890).

Otro aspecto es el hecho de una rica gama de experiencias carismáticas y movimientos eclesiales que después de la R.F. nacen por obra de algunos hombres y mujeres carismáticas (muchos de ellos canonizados) y que darán lugar a fundaciones religiosas y numerosas obras de caridad ${ }^{61}$. Tales «movimientos» eclesiales «carismáticos» necesitan ser encuadrados en la historia contemporánea: proceso de descristianización de la persona y de la sociedad, postura hostil del estado liberal frente a la Iglesia, supresión de la vida religiosa regular; numerosos signos de estancamiento y de decadencia de muchas antiguas realidades eclesiales (órdenes religiosas, etc....), El imponerse en muchas zonas del mundo regímenes anticristianos de matriz masónica algunos, de ideología totalitaria y estatalista autárquica otros.

¿Cuáles son los signos comunes a estos movimientos, campos fecundos para vocaciones a los diversos estados de la vida eclesial: sacerdocio, vida religiosa y consagrada o virginidad?62

a) en el siglo del positivismo y la creencia absoluta en el progreso como fruto autónomo de la inteligencia y actividad del hombre surgen en la Iglesia nuevos movimientos que afirman la centralidad absoluta de Dios, única esperanza del hombre, como subraya Benedicto XVI en la encíclica Spe salvi.

b) En un mundo cada vez más difícil por visiones de prepotencia y exclusión racial se extiende el culto al Corazón de Jesús traspasado en la cruz y Buen Pas-

60. F. González Fernández, Los Movimientos en la Historia de la Iglesia, Madrid 1999; A. Suquia, Seguir a Cristo hoy, Madrid 1992; Blachnicki - Chantraine - Corecco, I Movimenti della Chiesa negli anni 80, Milano 1982; Biffi - Cordes - Errazuriz - Giussani - Moreira Neves - Suenens, I Movimenti nella Chiesa. Atti del $2^{\circ}$ Colloquio Internazionale, Milano 1987; F. Ciardi, I Fondatori uomini dello Spirito, Roma 1982; A. Favale, Movimenti ecclesiali contemporanei. dimensioni storiche teologiche-spirituali ed apostoliche, Roma 1980; L. Giussani, Un avvenimento di vita, cioè una storia. Prefazione del cardinale Joseph Ratzinger, Roma 1993; F. Gonzalez (ed), Annunciare Cristo all'Europa, Milano 1991; La Nuova evangelizzazione; Communio 124 (1992) (monográfico); A. ScolA, Avvenimento e tradizione. Questioni di Ecclesiologia. Milano 1987; M. M. Bru, Testigos del Espíritu. Los nuevos líderes católicos: movimientos y comunidades,1998; P. J. Cordes, Segni di speranza, Cinisello Balsamo 1998.

61. Remito a F. González, Los movimientos en la historia de la Iglesia, Madrid 1999.

62. Cf. L. Giussani, Il tempo e il tempio. Dio e l'uomo, Milano 1996 y 2008. 
tor, esto es, la salvación ofrecida a todos y en el momento álgido del totalitarismo y al comienzo de un restablecimiento del valor y la dignidad de la persona.

c) La Iglesia descubre con fuerza la potencia de la Palabra de Dios y la propone con renovado vigor en los diversos movimientos.

d) En una comunidad eclesial con esta autoconcienza la caridad deviene siempre obra concreta; se ve con fuerza especialmente viva en el nacimiento y desarrollo del movimiento misionero «ad gentes». También la comunidad eclesial se ve interpelada por las situaciones sociales emergentes con especial gravedad, como en la llamada «cuestión social» y otras que se muestran especialmente graves en la época contemporánea. Lo hace con respuestas concretas de los cristianos llamados también con vocación específica para cada situación, un hacer presente a Cristo de mil maneras, como recuerda la Lumen Gentium hablando de la vida religiosa (cap. VI). Los cristianos sienten dolorosamente el peso de las divisiones que contradicen la pertenencia única a Cristo y el signo de la misma. Nace así el movimiento ecuménico, lento y tortuoso al comienzo, sobre todo por una larga historia de contradicciones, malentendidos y fuertes prejuicios.

Todo este rico mosaico de realidades cristianas demuestra la presencia del Espíritu de Cristo actuando en su Iglesia, a pesar de los pecados de algunos entre aquellos llamados a ser «sal de la tierra, luz y ciudad visible sobre el monte» (cf. Mt 5, 13-16). En el último siglo el Magisterio ha profundizado progresivamente en el tema vocacional también de los laicos en la Iglesia. Se ha dado cuenta de cómo el «Espíritu hablaba a las Iglesias» (cf. Ap 3, 22) sea con una atenta «lectura de los signos de los tiempos», como nos enseña el Vaticano II en el campo ecumenico (cf. Unitatis Redintegratio, I, n. 4) sea a través de los movimientos de renovación en el seno de la comunidad eclesial y en los acontecimientos de la historia abriéndose totalmente a la realidad ${ }^{63 .}$ Será precisamente, a partir del pontificado de Pío XII en un crecimiento más neto cuando los laicos son llamados a una verdadera corresponsabilidad en el apostolado, que el Vaticano II claramente focaliza en sus documentos especialmente en el Decreto Apostolicam actuositatem. Serán a continuación estos «movimientos» los que pondrán el acento, la teología bautismal y el Misterio de Comunión de la Iglesia como hace el Vaticano II.

Estas realidades son un terreno fértil para el nacimiento y crecimiento de vocaciones para el sacerdocio y para la vida consagrada; en este caso con formas asociativas inéditas de consagración ${ }^{64}$. De hecho raramente se encuentran hoy movimientos eclesiales que no hayan unido realidades de consagración virginal, de promoción de vocaciones sacerdotales con formas asociativas variadas. Todo

63. Presbyterorum Ordinis II, 9, invita a los presbíteros a reconocer los signos de los tiempos: Io reitera Gaudium et spes, 4, hablando del deber de la Iglesia de escrutar los signos de los tiempos e interpretarlos a la luz del Evangelio, y discernir en los acontecimientos del mundo los verdaderos signos de la presencia o designio de Dios (11).

64. Cf. F. González, Los movimientos eclesiales en la historia de la Iglesia, .239-295. 
este conjunto de cosas nos indica cómo en la Historia de la Iglesia nos encontramos hoy frente a una nueva fase histórica también en la historia de la promoción vocacional y de la formación sacerdotal y de la vida consagrada.

\section{NOTAS CONCLUSIVAS}

Quisiera concluir estas notas señalando algunos apuntes sugeridos por la mirada a la historia de la Iglesia. En la existencia cristiana se pueden señalar tres aspectos en la misma: la vida cristiana como vocación, su dimensión de caridad y su apertura a todas las dimensiones de lo humano ${ }^{65}$.

-Como vocación. En este camino de la vida como vocación, Dios nos llama en Cristo a un seguimiento que nunca es abstracto. El hombre por sí solo no encuentra jamás la energía necesaria para seguir con seguridad un camino. He aquí por qué es necesaria siempre la acción del Espíritu que superó la pusilanimidad de los apóstoles y los lanzó al mundo para dar testimonio de la Resurrección de Cristo y su co-prensencialidad en nosotros (cf. Mt 28, 20). El descubrimiento de Cristo como centro de toda realidad elimina el temor y permite al hombre ser testigo suyo incluso frente a la adversidad («vosotros sois de Cristo y Cristo es de Dios», 1 Cor 3, 23). Toda vocación sigue las huellas seguras de Cristo y concibe todo en la vida al servicio del diseño sobre el cosmos en el que Cristo es la cabeza de toda realidad (Col 2, 17).

Darse cuenta de la propia vocación, concebir la propia experiencia como servicio en todo es el compromiso del propio ser al cual el Espíritu de Cristo nos llama y da la fuerza para iniciarlo, dar los primeros pasos y seguirlo en fidelidad. Todo esto es lo contrario de la mentalidad moderna que nos educa a mirar el futuro con los criterios del instinto, del provecho, del gusto, del placer y de la conveniencia inmediata. El vuelco que significa la vocación cristiana topa con la mentalidad del mundo (cf. Jn 15, 18 - 16, 1-4); es siempre una «con-versión» (un cambio de sentido). Esta mentalidad, así difundida, explica los obstáculos que las vocaciones al seguimiento de Cristo encuentran. Tal mentalidad es la fuente de los criterios inmanentes en esa sabiduría mundana, juzgada como «buen sentido»; se encuentra tan difundida que constituye la mentalidad común también en muchos bautizados. He aquí por qué los movimientos eclesiales hoy y las comunidades más vivas en la Iglesia se convierten cada vez más en terreno fértil de las vocaciones y la companía eficaz en su desarrollo: de cómo

65. Cf. L. Giussani, Tracce di esperienza cristiana, Milano 1960; nueva edición, I/ camino al vero è un'esperienza, Milano 2006, 83-206, donde dedica una serie de apuntes al método cristiano, temáticas que el fundador del movimiento eclesial Comunión y Liberación ha expuesto a lo largo de toda su vida de educador en sus numerosas obras nacidas precisamente más de la experiencia educativa que de obras sistemáticas en el sentido editorial del término. Cf. también L. Giussani - S. Alberto - J. Prades, Generare tracce nella storia del mondo, Milano 1998. 
un bautizado podrá servir con todo su ser a Aquel que es el Todo, al Reino. Tal es el único criterio educativo de una personalidad humana captada por Cristo, redimida y llena de la fuerza de su Espíritu. Son los niños, los adolescentes y la primera juventud, las etapas fundamentales del crecimiento humano, las etapas fundamentales del cecimiento de la persona, donde se puede normalmente desarrollar esta apertura al Misterio y a la vocación. Al inicio, normalmente, la vocación personal no se presenta como un mandato concreto, sino como una sugerencia, una invitación, como una posibilidad entrevista. Esto es aún más verdadero cuanto más fundamental e importante es la misión que será confiada a quien es llamado. La conciencia de cada uno, rectamente educada y ayudada, sugerirá discretamente, y a menudo no sin excitación, el camino a seguir. En este sentido cada uno tiene una responsabilidad personal ante la llamada, que él libremente acoge y sigue frente a tantas otras posibilidades. Pero también aquí entra el papel imprescindible del educador que con sabiduría evangélica y con discreción ayuda a la verificación vocacional de la persona, sobre todo frente a llamadas tan delicadas como la vida sacerdotal o la consagrada.

-Como caridad. La aceptación de la vida como vocación, en función del Todo, define la existencia como profundo compartir de la realidad por la cual originalmente se nace y de la cual continuamente se depende; destino profundo a tomar parte en ella, aceptándola y ofreciéndose a ella, en cuanto es la voluntad de Dios, a su Reino. La aceptación de la vida como vocación compromete la propia existencia en la caridad para que se cumpla el designio de Dios en Cristo.

-Como universalidad o apertura a todas las dimensiones de lo humano. Es connatural a la vocación cristiana, por su naturaleza, la apertura a la universalidad, en cuanto abarca todo ámbito y situación, sin restricciones. El seguimiento de Cristo comporta precisamente esta dimensión universal, no sólo en sentido geográfico, sino sobre todo en cuanto abarca todo aspecto de la existencia. Los límites puestos por el llamado molestan el completo seguimiento de Cristo, y por eso el amor, que no es efecto de un gusto, cálculo o plan propio, sino que consiste en la adhesión total a Cristo en la modalidad en que Él nos llama, como por otra parte vemos en las llamadas del Evangelio: en las positivas, cuando el llamado ha dejado todo, también las cosas humanamente más queridas como los padres o las propias profesiones o bienes; pero también negativamente, como en el caso del joven rico han querido condicionar el seguimiento y por eso se han retirado. De aquí se requiere que la característica esencial y la verificación de una vocación cristiana sea la ilimitada apertura a la voluntad divina y en la modalidad que ella disponga; este es ante todo el sentido de la universalidad.

Pero es necesario que también el compromiso verdaderamente humano se abra a todos, en cuanto que la humanidad pertenece a todos; una atención a la propia experiencia humana no es verdadera si se aleja de la experiencia de todos. Por esto se entiende el subrayado del amor a la propia humanidad en el cual 
el mismo Benedicto XVI insiste en sus intervenciones sobre el tema vocacional, como condición irrenunciable para toda vocación al sacerdocio, por ejemplo. Pero es necesario añadir que la perspectiva universal, la energía para seguirla son más un don que una conquista, dependen más de un encuentro que de una propia genial idea. Son fruto de la gracia del Espíritu Santo.

A la luz de la problemática tratada y contemplando a lo largo de la historia los rostros de Santos sacerdotes y religiosos se podrá captar mejor el sentido de la vocación sacerdotal y de la religiosa y la misión que Dios realiza en la Iglesia a través de los sacerdotes.

Concluyamos citando al entonces cardinal J. Ratzinger cuando escribía sobre el método de la difusión del cristianismo en los primeros siglos, sobre la fuerza interior del advenimiento cristiano y su continuidad excepcional: «La conversión del mundo antiguo al cristianismo no fue el resultado de una actividad planificada por la Iglesia, sino el fruto de una constatación de la fe, de experiencia a experiencia, la que ha constituido la fuerza misionera de la Iglesia antigua» ${ }^{66}$. Y el beato Juan Pablo Il en su encíclica en la conclusión del Año Santo de 2000 y en su visión para el nuevo milenio, contenida en la carta apostólica Novo millennio ineunte (6 enero 2001), propone un programa para todo tiempo; ha puesto la persona de Jesús en el centro de la gratitud y de la esperanza de la Iglesia. El tercer capítulo es titulado «Partir de Cristo» y declara con franqueza: «No nos seduce ciertamente la perspectiva ingenua que, frente a los grandes desafíos de nuestro tiempo, pueda ejercer una fórmula mágica. No, no nos salvará una fórmula, sino una Persona, y la certeza que ella nos infunde: '¡Yo estoy con vosotros!'» (NMI, 29). Nueve años después, en otra gran solemnidad del Señor, el Sagrado Corazón de Jesús, Benedicto XVI ha pronunciado una homilía donde se ha referido una vez más a la descripción joánea del costado abierto de Cristo, del cual mana sangre y agua (cf. Jn, 19, 34). En ella afirmaba con palabras que recuerdan la Novo millennio ineunte: «Todo cristiano y todo sacerdote debería, a partir de Cristo, convertirse en manantial que comunica vida a los otros. Nosotros deberíamos dar agua de vida a un mundo sediento ${ }^{67}$. Por eso, no son las fórmulas de resolver problemas, tampoco las vocacionales, sino el encuentro, Cristo, la gracia del encuentro con Él genera una experiencia de gracia y de vida nueva.

66. J. Ratzinger, Guardare Cristo. Esercizi di fede, speranza e carità. Milano 1989, 31.

67. R. P. Imbelli, L'audacia di Dio e l'opposizione del nemico: L'Osservatore Romano, 16 junio 2010. 